\title{
Progressão Continuada e Patologização da Educação: um debate necessário
}

\author{
Lygia de Sousa Viégas \\ Faculdade de Educação da Universidade Federal da Bahia - BA
}

\begin{abstract}
Resumo
O presente artigo analisa criticamente as repercussões da progressão continuada na escola, destacando os argumentos patologizantes que sustentam explicações individualizantes sobre o fracasso escolar no bojo dessa política. Para tanto, inicia apresentando um breve histórico da ideia de abolir a reprovação nas escolas públicas brasileiras. Em seguida, desvela aspectos do discurso oficial sobre a progressão continuada, tomando como caso a experiência paulista. Posto isto, apresenta pesquisa etnográfica realizada em uma escola pública, apresentando o método e parte dos seus resultados, especialmente as falas de professores e alunos e a dinâmica de sala de aula. Finalmente, tece considerações sobre o fracasso escolar no âmbito da progressão continuada, articulando tal fenômeno com a patologização da educação. Espera-se, com o artigo, ampliar a análise dos impactos da progressão continuada na vida diária escolar da rede pública estadual paulista, caminhando na busca do enfrentamento efetivo dos problemas vivenciados no chão da escola.
\end{abstract}

Palavras-chave: Rendimento escolar; fracasso escolar; patologização.

\section{Continuous progression and pathologizacion of education:}

\section{An important debate}

\begin{abstract}
In this paper we analyse the impact of continuous learning progression on schools. We emphasize the pathologizacion arguments that support the current explanations around the school failure, in the core of this policy. For this purpose, we start presenting a brief history of the concept of eradicating the school failure in Brazilian Public schools. Then we reveal aspects of the official discourse about the continuous progression, using as example the model adopted by the city of São Paulo. Thereafter we present an ethnographic research conducted in a public school, giving emphasis on the speeches of teachers and students, as well as on the classroom dynamics. Finally, we display considerations on school failure in the scope of continuous progression, connecting such phenomenon to the medicalization of education.With this study we expect to broaden the analysis of the continuing progression and its impacts on the daily life in São Paulo public school system. We intent to move towards an effective solution of the problems experienced within the school walls.
\end{abstract}

Keywords: Academic achievement; academic failure; pathologizacion.

\section{Progresión Continuada y Patologización de la Educación: un debate necesario}

\section{Resumen}

El presente artículo analiza críticamente las repercusiones de la progresión continuada en la escuela, destacando los argumentos "patologizantes" que sostienen explicaciones individualizadores sobre el fracaso escolar en el bojo de esa política. Para tanto, inicia presentando un breve histórico de la idea de suprimirla reprobación en las escuelas públicas brasileñas. En seguida, desvela aspectos del discurso oficial sobre la progresión continuada, tomando como caso la experiencia paulista. Puesto esto, presenta investigación etnográfica realizada en una escuela pública, presentando el método y parte de sus resultados, especialmente las hablas de profesores y alumnos y la dinámica de sala de clase. Finalmente, se hace consideraciones sobre el fracaso escolar en el ámbito de la progresión continuada, articulando tal fenómeno con la patologización de la educación. Se espera, con el artículo, ampliar el análisis de los impactos de la progresión continuada en la vida diaria escolar de la red pública estadual paulista, caminando en la búsqueda del enfrentamiento efectivo de los problemas vivenciados no suelo de la escuela.

Palabras-clave: Rendimiento escolar; fracaso escolar; patologización. 


\section{Introdução}

O presente artigo objetiva analisar criticamente as repercussões do regime de Progressão Continuada na vida diária escolar, adotando como norte os processos de patologização da educação em marcha no contexto contemporâneo. A Progressão Continuada foi implantada em toda a rede pública estadual paulista por meio da Resolução SE N. ${ }^{\circ} 4$, de 15 de janeiro de 1998. A partir de então, o Ensino Fundamental foi reorganizado em dois ciclos de quatro anos (Ciclo I: de $1^{\mathrm{a}}$ a $4^{\mathrm{a}}$ série; Ciclo II: de $5^{\mathrm{a}}$ a $8^{\mathrm{a}}$ ), estando proibida a reprovação de alunos no interior de cada ciclo.

Após quinze anos de vigência desse regime as estatísticas educacionais paulistas dão conta de que a maioria das crianças progride continuamente pelos anos escolares, produzindo baixíssimos índices de reprovação. De fato, no ano de 2011, 92,9\% dos alunos do Ensino Fundamental foram aprovados (Secretaria de Estado da Educação, 2013), números comemorados pelo Estado como sucesso escolar; no entanto, índices do aprendizado dos alunos mostram a incongruência de supor que o fracasso escolar tenha sido superado no contexto da progressão continuada, reforçando a importância da preocupação com a qualidade do ensino oferecido. Dados do IDEB indicam que $54,1 \%$ dos alunos das séries iniciais do Ensino Fundamental paulista não atingiram a meta de aprendizagem em 2011 (Portal IDEB, 2013). No caso da Prova Brasil, apenas $42 \%$ dos alunos do $5^{\circ}$ ano obtiveram aprendizagem satisfatória em Português, índice que cai para 40\% no caso de Matemática (QEdu, 2013).

Neste contexto, revigora-se a importância de analisar os impactos concretos da progressão continuada na escola pública, o que faremos adotando como ponto de partida três eixos imbricados: os aspectos históricos, o discurso oficial e a vida diária escolar. Finalmente, a análise do fracasso escolar no contexto da progressão continuada será articulada com o debate em torno da patologização ou medicalização da vida.

Entende-se por medicalização “(...) a transformação de questões coletivas, de ordem social e política, em questões individuais, biológicas", processo que isenta as instâncias de poder de suas responsabilidades, embora trate de problemas gerados e perpetuados em suas entranhas (Moysés, \& Collares, 2010, p. 71-2). Assim, cabe apontar o risco de patologização dos impactos da progressão continuada, tarefa realizada ao final deste artigo, a partir dos três eixos mencionados anteriormente.

\section{Breve histórico do fim da reprovação na escola pública brasileira}

Embora a progressão continuada tenha sido apresentada como solução inovadora para contornar os altos índices de retenção, um estudo histórico revela que a ideia de abolir a reprovação vem sendo defendida no Brasil ao menos desde o início do século XX (Barreto, \& Mitrulis, 2001; Barreto, \& Sousa, 2004; Mainardes, 2007; Viégas, 2009).
Segundo Viégas (2009), no caso paulista este histórico divide-se em três momentos: a defesa no âmbito das ideias, a implantação experimental e sua adoção como política de governo em toda a rede estadual paulista. Como marco histórico, a autora destaca a carta aberta de Sampaio Dória, publicada em 1918 sob o título: "Contra o analphabetismo". É um documento raro, no qual o autor defende a promoção automática como forma de resolver o problema do analfabetismo sem onerar os cofres públicos com a ampliação de vagas. Na época, a proposta não foi implantada, e não se encontram publicações sobre o tema por um período de mais de 30 anos.

O debate retornou na segunda metade dos anos 1950, quando expoentes nacionais publicaram argumentos favoráveis ou contrários à proposta, com destaque para Almeida Junior (1957) o Presidente Juscelino Kubistchek (1957) e Dante Moreira Leite (1959). A primeira implantação da promoção automática no Estado de São Paulo, feita em caráter experimental, deu-se na virada para a década 1960, tendo como lócus o Grupo Escolar Experimental da Lapa (Antunha, Lombardi; \& Bueno, 1961). Tal experiência foi analisada por Viégas e Souza (2012) em artigo no qual são apresentados documentos de implantação, publicações da época e depoimentos de educadores naquele contexto.

Seguem-se a essa experiência as primeiras implantações como política de governo em toda a rede de ensino paulista: a Reforma do Ensino Primário, em 1968 e o Ciclo Básico, em 1984, o qual foi complementado pela Progressão Continuada em 1998. Neste sentido, um estudo histórico revela que a proposta de abolir a reprovação nas escolas paulistas não é novidade, fato do qual se depreende que o fracasso escolar, embora seja um problema antigo, perdurou de forma crônica mesmo no bojo das políticas anteriores de abolição da reprovação.

Vale lembrar que a ideia não nasceu no Brasil, mas foi importada, sobretudo dos Estados Unidos e da Inglaterra. Diferentemente do que ocorreu nesses países, em solo brasileiro ela atendeu a demandas locais, sendo vista como meio econômico de achatar a reprovação; porém, mesmo defendendo esse caráter, pesquisadores destacam a importância de se garantirem condições objetivas para seu sucesso, centradas na infraestrutura da escola; no preparo de professores, alunos e famílias e em formas democráticas de implantação.

No âmbito do desenvolvimento infantil, é notável a compreensão de que a desigualdade social é reflexo das diferenças individuais. Tal lógica é sustentada por uma visão biologizante, que naturaliza processos sócio-históricos complexos, fato que, por sua vez, caracteriza o olhar medicalizante sobre a vida humana (Guarido, 2010).

\section{A Progressão Continuada no discurso oficial: o caso paulista}

Entre os documentos que sustentam a implantação da Progressão Continuada destaca-se o Parecer N. ${ }^{\circ} 8 / 97$ do Conselho Estadual de Educação (1997). Nele o argumento 
central focaliza os altos índices de reprovação e defasagem série/idade, apontados como incompatíveis com a democratização do ensino. As críticas à reprovação partem das perspectivas educacional, psicológica e econômica, esta última mais acentuada:

Uma mudança dessa natureza deve trazer, sem dúvida, benefícios tanto do ponto de vista pedagógico como econômico. Por um lado, o sistema escolar deixará de contribuir para o rebaixamento da autoestima de elevado contingente de alunos reprovados. Reprovações muitas vezes reincidentes na mesma criança ou jovem, com graves consequências para a formação da pessoa, do trabalhador e do cidadão. Por outro lado, a eliminação da retenção escolar e decorrente redução da evasão deve representar uma sensível otimização dos recursos para um maior e melhor atendimento de toda a população. A repetência constitui um pernicioso 'ralo' por onde são desperdiçados preciosos recursos financeiros da educação. O custo correspondente a um ano de escolaridade de um aluno reprovado é simplesmente um dinheiro perdido. Desperdício financeiro que, sem dúvida, afeta os investimentos em educação, seja na base física (prédios, salas de aula, equipamentos), seja, principalmente, nos salários dos trabalhadores do ensino. Sem falar do custo material e psicológico por parte do próprio aluno e de sua família (p. 151-2, itálicos nossos).

Segundo o Conselho Estadual de Educação, esta política fundamenta-se em dois grandes eixos: flexibilidade na organização da Educação Básica e mudança na concepção da avaliação escolar, que deixaria de ter caráter punitivo e passaria a ter caráter diagnóstico.

Análise crítica do discurso oficial no contexto de implantação da Progressão Continuada feita por Viégas e Souza (2006) mostra seu caráter ideológico: o interesse financeiro sobrepõe-se ao pedagógico, a defesa de que o possível fracasso da política seria decorrência da resistência dos professores a mudanças e a compreensão de que os alunos da rede pública pertencem a uma parcela da população que teria, naturalmente, problemas sociais e familiares que interfeririam na capacidade de aprender. Tais explicações, obviamente, tiram do Poder Público a responsabilidade pela qualidade da educação oferecida.

\section{Método}

Para se conhecer como a Progressão Continuada está sendo colocada em prática, foi realizada uma pesquisa etnográfica durante o ano letivo de 2004, por se entender que, para conhecer os impactos de um programa educacional desse porte é preciso pousar no "chão da escola", conviver longamente com quem a constrói. O contato face a face com a complexidade da vida escolar permite uma compreensão densa de sua dinâmica (Ezpeleta, \& Rockwell, 1986; Bogdan, \& Biklen, 1994; André, 1995).
Participou da pesquisa uma escola de ciclo I do Ensino Fundamental situada no centro da cidade de São Paulo - mais especificamente, duas turmas do último ano do ciclo I, com 35 alunos e uma professora cada. $O$ trabalho de campo somou aproximadamente 120 horas, envolvendo: 30 observações em sala de aula; análise de documentos escolares dos alunos; dois encontros em grupos com os alunos acompanhados (em média, sete alunos por grupo), com duração de uma hora e meia cada, realizados entre os meses de setembro e novembro de 2004; entrevistas gravadas com as professoras; encontro em grupo com familiares dos alunos acompanhados, realizado no mês de dezembro, com duas horas de duração. Todos os passos do campo foram registrados em relatos.

A análise do material seguiu as recomendações de Michelat (1980) e Lüdke e André (1986), que compreendem a leitura e releitura do material até chegar a uma impregnação, a eleição de categorias empíricas e a elaboração de categorias analíticas. O referencial teórico adotado é a Psicologia Escolar na perspectiva crítica.

Esta abordagem da Psicologia foi introduzida no Brasil por Maria Helena Souza Patto e é marco significativo seus livros "Psicologia e Ideologia" (1984) e "A produção do fracasso escolar" (1990). Segundo Patto, a Psicologia contribuiu hegemonicamente para a análise psicologizante da realidade escolar, não raro culpando e patologizando professores e alunos pela histórica situação de fracasso da escola pública. A partir de suas críticas, foram empreendidos esforços para imprimir novos rumos à área, merecendo destaque publicações de Machado e Souza (1997), Tanamachi, Proença e Rocha (2000), Meira e Antunes (2003) e Souza (2007).

\section{A progressão continuada na vida escolar}

Inicialmente, deve-se destacar que as classes pesquisadas eram compostas, em sua maioria, por alunos com a mesma idade, pois viveram a trajetória escolar no bojo da progressão continuada, sem reprovações. Além disso, em sua maioria estes alunos sempre estudaram na escola pesquisada, sendo acompanhados longitudinalmente pela equipe pedagógica, o que é um caso, se não típico, ao menos previsto, ou mesmo esperado.

Sobre como definiam suas turmas as professoras disseram:

Professora 1: É uma sala que tem diversos níveis de... aprendizagem, indo do mais fraco, do mais lento, do... com mais dificuldade de atenção, até aquele que caminha sozinho. São vários patamares de aprendizagem. Daquele que não sabe nada, que não tem... quase nada de base, até aquele que já está preparado para fazer uma $5^{\mathrm{a}}$ série excelente. Então, é uma sala bastante misturada.

Professora 2: É uma classe... heterogênea. Tem uns 12 alunos bons, uns quatro "nota 10 "... E os outros são todos 
problemáticos. Eles têm problemas sérios. Aprendizagem, comportamento, história de vida, tudo complicado. O problema maior, aqui, é... comportamento. Problema familiar... Quase todos fazem acompanhamento psicológico. Problema de fono, muito grave! Praticamente todos têm algum tipo de... deficiência.

Assim, as professoras caracterizam suas turmas pela heterogeneidade, mas tendem a definir essa diversidade a partir dos alunos, sob a lógica da dificuldade ou deficiência individual, não a relacionando aos impactos da Progressão Continuada.

Apesar de reconhecerem a heterogeneidade no nível de conhecimento dos alunos, as aulas seguiam um formato bastante tradicional, homogeneizante: carteiras enfileiradas, professoras enchendo a lousa de cópias dos livros, para serem copiados nos cadernos pelos alunos, em silêncio. Obviamente, alguns faziam a tarefa com mais desenvoltura e outros nem sequer compreendiam o que estava sendo copiado. Para atender à diversidade, por vezes a professora dividia a lousa em diversas lições, produzindo confusão; outras vezes, a aula seguia devagar, para tornar possível a integralização da tarefa por parte dos "mais lentos", deixando os "mais rápidos" ociosos. Também o comportamento dos alunos era diverso: havia aqueles que tendiam a obedecer mais facilmente à ordem de silêncio e produção e aqueles que se distraíam, conversavam, brincavam ou bagunçavam.

Boa parte do tempo era tomada pelas broncas das professoras nos alunos, às vezes mais presentes do que os conteúdos e motivadas por várias situações: conversar, brincar, brigar, circular pela sala, não fazer a lição, vestir ou tirar o agasalho, estar doente, faltar à escola, perguntar "fora de hora", ajudar ou humilhar o colega, errar a questão, demonstrar dúvidas e solicitar a participação na atividade ou responder a perguntas feitas a outros alunos. A análise quantitativa revelou a média de uma bronca a cada quatro minutos da aula observada.

Além de ouvir as professoras e observar as aulas, a pesquisa ouviu o que os alunos pensavam sobre a progressão continuada, contexto em que se constatou que a maioria era contrária aos preceitos dessa política. Eis algumas opiniões:

Silvia': Eu prefiro repetir, porque se a gente não repetir, a gente não vai ter a nossa vida, a nossa independência.

Márcio: Acho que se não passa é porque não está preparado. Não é que a professora quer mal de você.

Vicente: Qual é o problema de repetir? Não aprendeu, tenta de novo!

llana: É ruim, porque fica com a consciência pesada, que não se esforçou.
Com relação a essas falas, cumpre ressaltar que ao longo da pesquisa os alunos manifestaram mais preocupação em aprender do que em defender uma escola que reprova, enquanto na nova ordem educacional as opções vislumbradas são "passar sem aprender" ou "reprovar para aprender". Assim, fica compreensível a escolha pela segunda opção.

No decurso dos encontros em grupos foi solicitado aos alunos que escrevessem redações individuais. O material indica que muitas não correspondiam às expectativas em relação ao uso da norma oficial da língua, como é o caso das redações abaixo:

Silvia: Na 5 série tem 8 profas e para alicão vai oto profa e apago a alicão e para oto alicão e alicão de fideche o profo é um chato e lavo e a profa da atica é chata e ela minha contou que a 8 e 5 série é assim.

Gustavo: É chato porque os professores. ruí porque tei que acota sedo. na da tepo. e arora do requeio. é chado se fo poco. e os maiores quere a chaque e o tau. e gostade bade.

Gledson: A $5^{\mathrm{a}}$ série e munto difiço. Porque tem com ta difiço as provas sam deficil. $\mathrm{E} u$ acho que a. professora e $\mathrm{u}$ acho que a professora é prava da quinta série.

Emília: Que passar pralar para, $5^{\text {a }}$ série vai ser muito difícil. porriso eu vou temtar, passar e se eu passar eu vou iscrever tudo que a professora, passar, na lousa. e eu vou gostar muito de tar na $5^{\mathrm{a}}$ série, que ver ser legal e daora. e eu vou ser muito feliz e toda minha familía. e a minha mãe vae ficar muito feliz que vau medar um monte de beijos.

Além da forma errada, as redações trazem um conteúdo comum, incluindo aqui as demais redações recolhidas: a $5^{a}$ série é chata, as professoras são bravas e chatas, não dão tempo para fazer as atividades, é difícil. Essas descrições comunicam a maneira como essas crianças estão vivendo a experiência escolar, enfatizando que é uma experiência sofrida e com pouco sentido pedagógico, aspectos discutidos mais adiante.

Muitos alunos, familiares e professores atribuíam as dificuldades de alguns alunos a aspectos individuais: problemas de aprendizagem, distúrbios neurológicos, desinteresse familiar... Alice é um caso simbólico: com idade compatível com a série em que estava estudando, a aluna estudou todo o Ciclo I na escola pesquisada, sendo reprovada no final daquele ano, a pedido da mãe, com anuência da professora. Disse a professora:

A Alice é uma aluna muito..., que necessita de muita... atenção mesmo, que precisa de um acompanhamento muito... próximo. Ela tem muita dificuldade. Ela vai ser retida. A mãe é muito presente, está sempre aqui, querendo saber como ela está.

Em conversa da pesquisadora com a mãe, esta disse:

1 Os nomes são fictícios. 
Eu insisti para que Alice ficasse reprovada, para ver se assim ela progride. Alice é muito desinteressada, se não puxar, ela não estuda. Vou levar ela no médico para ver se ela é normal. Ela fica sempre desatenta com as coisas...

Curioso notar que a redação de Alice, apresentada abaixo, difere, em termos de qualidade, das citadas acima, pois está melhor estruturada e elaborada. Vejamos:

A $5^{\text {a }}$ série Ela tem cada professor um prosor de matemática um profesor de protugués um professor de História um profesor de ciencias um profesor de geografia e também a minha amiga falou que a gente tem que cesforça também tem que ler muito e aprender a escrever muito também, para a gente paçar de ano porque se agente não ficar burra que nem uma memdinga. Até lógo galera.

Também quanto ao comportamento Alice não diferia dos colegas: distraía-se, não parava quieta, como todos. Nada que chamasse a atenção. Por que, então, a suspeita em relação à sua normalidade? O fato é que, quando cursava o $3^{\circ}$ ano, Alice foi encaminhada pela professora para avaliação psicológica, cuja síntese, presente em sua documentação escolar, se não produziu essa suspeita, certamente a reforçou:

I) Motivo do estudo: Alice encontra-se em acompanhamento psicológico desde março de 2003, tendo sido encaminhada pela professora da escola com queixas relacionadas à "grande dificuldade de concentração, imatura, insegura e com muita lentidão de raciocínio". Na entrevista com a mãe, a queixa foi centrada na preocupação com a filha, visto que ela "não se interessa pela escola, é agressiva, não consegue aprender o que ensinam". II) Histórico: Alice foi adotada aos 2 anos. Tem conhecimento da condição de criança adotada, conhece a mãe biológica, mas não tem relação com ela. Não foi possível obter com precisão dados da anamnese. Segundo a mãe, o desenvolvimento psicomotor parece normal. Andou com 1 ano, embora quedas com freqüência. Aos 9 meses, infecção intestinal seguida de febre alta. Com 1 ano de 2 meses, teve pneumonia. Com 2 anos, queda de escada de 22 degraus, tendo sido atendida em hospital e submetida à sutura do ferimento e RX. III) Avaliação psicológica: a avaliação psicológica mostrou que Alice apresentava alto grau de ansiedade, forte insegurança, rebaixada autoestima, inibição da personalidade, certa desorganização do funcionamento intelectual e comportamento de atuação (Bender), seguido de reações agressivas, configurando um comprometimento no plano afetivo e emocional com prejuízo para sua adaptação social e seu desenvolvimento. A avaliação psicopedagógica revelou: "função gestáltica visomotora comprometida e dificuldade de aprendizagem com comprometimento da área cognitiva". No decorrer do acompanhamento, Alice conseguiu assimilar razoavelmente as terapias. Evoluiu com melhora da ansiedade e do comportamento agressivo, porém ainda encontra-se muito dispersa, com dificuldade de atenção, concentração e muita lentidão de raciocínio. Entende e obedece ordens, mas necessita de muita estimulação para manter-se atenta e não se dispersar nas atividades. No entanto, expressa desejo de crescer, demonstra estar consciente de suas dificuldades e se esforça para obter simpatia e afeto dos que a cercam. IV) Conclusão/Encaminhamento: De acordo com os dados levantados, conclui-se que o baixo desempenho escolar de Alice parece estar relacionado com aspectos emocionais e cognitivos, necessitando manter o acompanhamento psicológico e psicopedagógico, na tentativa de ajudá-la a corrigir essas dificuldades. Para descartar possível alteração cerebral, Alice está sendo encaminhada para avaliação e conduta com neurologista. (destaques nossos).

Alguns aspectos dessa avaliação serão discutidos, ainda que brevemente. Chama a atenção que, embora Alice tenha sido encaminhada pela escola e sua mãe afirme que ela não se interessa pela escola, o histórico feito pela psicóloga restringe-se aos dois primeiros anos de vida, focalizando as doenças que ela teve nesse período, desconsiderando assim a complexidade da vida escolar, sobretudo os impactos da Progressão Continuada no seu processo de escolarização. A avaliação psicológica, por sua vez, foi construída a partir de testes psicológicos, sem descrever como se deu esse processo. Ao contrário, a psicóloga se limitou a desfilar uma série de onze traços negativos da criança, concluindo que o fracasso escolar parece estar relacionado com aspectos emocionais e cognitivos, e sugerindo, por fim, o encaminhamento para avaliação neurológica.

Conforme dito anteriormente, Alice não se diferenciava dos colegas, tanto em termos de aprendizagem quanto de comportamento. A aluna tinha a mesma condição de acompanhar uma $5^{\mathrm{a}}$ série que tinham seus colegas, mas a mãe e a professora defenderam a sua reprovação, com base na possível anormalidade da criança. A avaliação psicológica, por sua vez, corrobora a patologização de sua escolarização, por isso é preciso discutir os impactos da medicalização na vida escolar sob a égide da progressão continuada.

\section{Progressão Continuada e medicalização da educação}

A forma como alunos são vistos e tratados em tempos de Progressão Continuada é a mesma apresentada por Patto, em "A produção do fracasso escolar: histórias de submissão e rebeldia" (1990), livro que aponta as entranhas do fracasso escolar na rede pública brasileira, que tende a aparecer como culpa do "aluno fracassado". Também não difere das histórias descritas por Moysés (2001), cuja pesquisa desconstrói mitos medicalizantes do fracasso escolar a partir da escuta atenta das crianças e suas famílias. Por fim, assemelha-se ao perfil clássico de alunos encaminhados para psicólogos pela escola, analisados em profundidade por Souza (2002). Em comum, tais pesquisas apontam um olhar marcado pela medicalização do fracasso escolar, que entende os problemas de aprendizagem ou de compor- 
tamento de forma individualizante e descontextualizada, reproduzindo preconceitos (Collares, \& Moysés, 1996) - visão que é preciso desconstruir, tarefa empreendida a seguir.

\section{Dificuldade de aprendizagem e o lugar do conhecimento}

Se há um tema que comparece sempre que a Progressão Continuada está em pauta é a questão do aprendizado dos alunos no bojo dessa política de governo. Concretamente, a pesquisa revelou a presença de alunos na $4^{a}$ série com dificuldades importantes de leitura, escrita e domínio da matemática, advindas de um processo de escolarização precário. Assim, explicita-se que a Progressão Continuada não superou o fracasso escolar - ao contrário, o problema persiste, embora invisível para quem não tem um contato direto com a realidade da escola pública no Estado de São Paulo.

Tal constatação é corroborada por diversos pensadores importantes no campo educacional brasileiro, com destaque para Patto (2005), para quem "(...) na concepção dos planejadores, democratizar a escola tem sido principalmente abrir a porta trancada das séries subsequentes, importando pouco a qualidade do ensino oferecido" (p. 195).

O próprio discurso oficial reconhece a existência de alunos nessas condições, mas culpa os professores, vistos como desinteressados, acomodados e resistentes (Conselho Estadual de Educação, 1997). Por sua vez, as explicações das professoras e de parte dos alunos pesquisados sobre essa situação culpam os alunos semiformados, definindo-os como crianças com problemas individuais ou familiares.

Souza (2002) destaca a importância de diferenciar, inclusive semanticamente, as chamadas "dificuldades de aprendizagem", supostamente localizadas no aprendiz (ou, quando muito, na sua família), das "dificuldades de escolarização", expressão que desloca o olhar, passando a considerar a participação de outros aspectos envolvidos na dificuldade apresentada pelo aluno, sendo a escola importante agente. Isto significa que, se o problema não se limita ao aluno, sua solução pede intervenção mais ampla do que o simples encaminhamento para profissionais na área de saúde.

Supor que o problema se circunscreve ao aluno é dar continuidade à história de exclusão, sobretudo da população pobre, em relação ao processo de escolarização bem-sucedido. Na contramão desse olhar, destaca-se a importância de se repensar a escola e sua dinâmica de funcionamento. Assim, Souza (2002) defende a ampliação da concepção sobre a escola, saindo dos limites estreitos da mera socialização e destacando seu papel político, especialmente no que se refere à efetiva democratização do estado.

O bom cumprimento desse papel não abre mão dos conteúdos básicos em uma sociedade letrada: ler e escrever, e, mais do que isso, compreender crítica e ativamente a sociedade em que vivemos. Saviani (2005), ao elaborar a "Pedagogia Histórico-Crítica", contribui com essa reflexão partindo do princípio de que "(...) o trabalho educativo é o ato de produzir, direta e intencionalmente, em cada indivíduo singular, a humanidade que é produzida histórica e coletivamente pelo conjunto dos homens" (p. 13). Esse educador destaca que o objeto da educação é identificar os elementos culturais necessários para essa formação e ao mesmo tempo descobrir formas adequadas de realizá-la.

Nesse processo, cabe à escola o papel de socializar o saber sistematizado ao longo da história e tido como fundamental para a formação humana - ou seja, ela deve ensinar conteúdos: "É a exigência de apropriação do conhecimento sistematizado por parte das novas gerações que torna necessária a existência da escola" (Saviani, 2005, p. 15).

Saviani (2005) destaca que não se trata de defender a escola tradicional, na qual os conteúdos são mecânicos e vazios de sentido; ao contrário, os conteúdos devem estar a serviço da formação em sentido mais amplo: "O povo precisa da escola para ter acesso ao saber erudito, ao saber sistematizado e, em consequência, para expressar de forma elaborada os conteúdos da cultura popular que correspondem aos seus interesses" (p. 80). De modo semelhante, Duarte (2004) destaca:

Não se trata de defender uma educação intelectualista nem de reduzir a luta educacional a uma questão de quantidade maior ou menor de conteúdos escolares. A questão é a de que, ao defender como tarefa central da escola a socialização do saber historicamente produzido, a pedagogia histórico-crítica procura agudizar a contradição da sociedade contemporânea, que se apresenta como a sociedade do conhecimento e que, entretanto, ao contrário do que é apregoado, não cria as condições para uma real socialização do saber (p. 9).

Por esse motivo Duarte (2004) defende que "No caso da educação escolar, trata-se de resistir a todas as artimanhas da ideologia dominante, que resultam em processos objetivos pelos quais a sociedade contemporânea lança as massas não só na miséria material mas também na miséria intelectual" (p. 8).

Finalizando, cabe esclarecer que o esvaziamento da escola como instituição que socializa o conhecimento historicamente sistematizado não era oriundo das professoras acompanhadas, mas da própria essência da Progressão Continuada como política de governo cuja meta é baratear a escola, e não melhorar sua qualidade.

\section{Problemas de comportamento e o lugar do disciplinamento}

Acompanhando o esvaziamento dos conteúdos escolares, está a centralidade do disciplinamento dos alunos. Em uma estrutura que é historicamente calcada na cobrança e na qual os professores não podem mais cobrar conhecimento, resta cobrar o comportamento, o que significa, sobretudo, obedecer a ordens e não se manifestar, verbal ou fisicamente. 
A finalidade de docilizar os corpos dos alunos é tão antiga quanto a própria instituição escolar, que foi mesmo autorizada a utilizar a palmatória em alunos considerados indisciplinados e desobedientes. Tal estrutura escolar vem sendo alvo de críticas contundentes no Brasil, sobretudo a partir da década de 1980 (Patto, 1990).

Hoje, (quase) não há professores utilizando castigos físicos, mas o autoritarismo na relação professor-aluno permanece. Os alunos passam o turno escolar quase inteiro obedecendo a ordens abstratas, inquestionáveis, muitas vezes feitas aos gritos, além de terem seus movimentos e palavras impedidos: devem ficar sentados em silêncio, e se não procederem assim, levam broncas. Esse foi o formato dominante nas observações em sala de aula.

Em "Psicologia e Ideologia" (1984), Patto chama a atenção para a participação ativa da escola no "processo de cassação da palavra do oprimido", por meio de programas educacionais que impingem aos alunos um jeito de falar, pensar e agir que bloqueia sua expressão autêntica. Segundo a autora, aos alunos pobres restam duas possibilidades: "desistir (calar em classe ou abandonar a escola, após algumas reprovações) ou esforçar-se para corresponder e assimilar os padrões impostos" (p. 138).

Cabe aqui perguntar: que efeitos uma trajetória escolar de silenciamento e autoritarismo produz na formação de alunos, e mesmo de professores? Gonçalves Filho (2007) destaca existirem relações que pressupõem a discrepância, como é o caso da relação entre professores e alunos, já que é de se esperar que o professor seja uma autoridade; no entanto o autor diferencia relações de autoridade daquelas sustentadas no autoritarismo: “(...) melhor seria que as caracterizássemos como formas de dependência passageira, dependência para a independência". Segue dizendo (p. 211):

Pais e professores, quando despóticos, não apenas embaraçam ou impedem o caminho do cidadão, como também concorrem para tornar entrópica a relação pedagógica ela mesma, deixando filhos e aprendizes infantilizados e incompetentes. Educar para a cidadania é condição mesma para que educação seja educação, incremento e não violação de aptidões e saberes.

Por sua origem política e por seus efeitos nocivos, cabe questionar o contorno autoritário e humilhante que dá forma ao cotidiano nas salas de aula, o qual, embora tenha origem antes da Progressão Continuada, não apenas não é transformado nesse novo contexto escolar, mas principalmente, encontra nele importante catalisador. Nesse sentido, além de negar aos alunos o direito à escolarização de qualidade, nega-se-lhes também o direito de falar e agir, imposto pelo silenciamento maciço de sua expressão, o que dá continuidade à longa história de humilhação sofrida por sua classe. Tratar esse contexto multideterminado como reflexo de problemas individuais dos alunos (sejam biológicos, psíquicos ou sociais) é terreno fértil para a medicalização da escola.

\section{Considerações finais}

Segundo Patto (2005), o fim da reprovação "a qualquer preço" implicou em um "prejuízo flagrante" para alunos: "(...) antes, a exclusão era sumária, agora é mais demorada e mais sutil. Em ambos os casos, o resultado último continua sendo a responsabilização a vítima”. Com isso, “(...) a grande decepção virá quando, de posse de um diploma de segunda classe, perceberem que continuam cidadãos de segunda classe" (p. 54). Assim se revelam os malefícios de uma política enaltecida pelo Estado.

O fato é que, passados mais de vinte anos de críticas contundentes à implantação de políticas públicas de forma autoritária, mantém-se inalterada a postura oficial de não ouvir e formar professores para a nova realidade, deixando-os à deriva.

Passados mais de vinte anos de duras críticas à escola pública oferecida, mantém-se inalterada a dinâmica tradicional, calcada, sobretudo, em cópias enfadonhas e nas broncas em alunos. O que muda é que, no novo contexto, não é permitido reprovar os alunos.

Passados mais de vinte anos de críticas ao preconceito entranhado nas escolas, alunos e familiares seguem sendo considerados os maiores "culpados" pelo fracasso escolar. Tal olhar atravessa parte dos textos históricos sobre o tema, alcança o discurso oficial e impacta diretamente a escola sob a égide da Progressão Continuada: diante de alunos que não consigam aprender ou se concentrar nas aulas, desconfia-se de sua capacidade de aprender e a dos familiares de educar, mantendo-se ilesa a estrutura imposta.

Para enfrentar esse continuísmo repetitivo, urge enfrentar alguns desafios, sempre lembrando que criticar a Progressão Continuada não é sinônimo de defender o retorno à escola que reprova, mas significa não perder de vista que a escola é a instituição responsável por ensinar o conhecimento sistematizado ao longo da história e garantir o aprendizado dos alunos, e sem isto, o acesso e a permanência não passam de engodo.

O esvaziamento dos conteúdos é complexo. Desde a primeira defesa da "promoção automática", autores afirmam que os conteúdos não são fundamentais, com destaque para Sampaio Dória (1918), que defende ser o principal papel da escola dar disciplina moral aos alunos. Além disso, no contexto atual, parece que o próprio Poder Público não se apropria dos estudos e pesquisas produzidos sobre a Progressão Continuada, construindo um discurso que ignora a história e o dissenso sobre o tema.

Talvez seja imbuído desse olhar que o Poder Público ignora a necessidade de formação docente para enfrentar uma mudança do porte da Progressão Continuada, supondo que os professores o aprenderão na prática. Assim alcançamos uma escola que, sem elaborar o passado, sem formação docente e sem condições para uma mudança desse quilate, já não forma os alunos para as letras, os números e o exercício crítico da cidadania. Nesse contexto, não é de estranhar que se reforce a visão de que alunos que não conseguem aprender têm um problema individual, dando 
continuidade, assim, à patologização das dificuldades de escolarização.

A segunda reflexão remete à centralidade da escola no disciplinamento dos alunos, que passa a ocupar o lugar vazio da aprendizagem. A partir da pesquisa de campo destaca-se que nem como instituição meramente socializadora a escola tem funcionado a contento. O que se nota, por exemplo, é a insistente estratégia de silenciar as conversas, e no limite, separar alunos que possuam vínculo de amizade. A impressão que isto passa é que educar crianças, na escola pública atual, é visto como sinônimo de domesticá-las; ou seja, a educação que se dá tem o mesmo olhar conservador que tem a escola tradicional. Nesse contexto, não é de estranhar que se repita a tese de que alunos que não se ajustem às regras escolares possuem distúrbios de comportamento e devem ser medicados.

Essas são contradições que se fazem presente nas escolas há muitas décadas. O que se observou na escola acompanhada em nada difere do que há muito vem sendo apontado em relação à rede pública estadual paulista. Repete-se a mesma preocupação econômica na construção de políticas educacionais, repete-se o mesmo olhar preconceituoso em relação aos professores, alunos e familiares, repete-se o autoritarismo na implantação de políticas de governo. Repetem-se os mesmos dilemas, as mesmas dificuldades, as mesmas queixas no interior da escola. Repete-se o mesmo funcionamento escolar, calcado em tarefas mecânicas e pouco interessantes. Repete-se a culpabilização dos alunos e famílias pelas dificuldades de escolarização, muitas vezes sustentadas em prontuários escolares que repetem o que sempre se disse sobre eles. Repetem-se discursos patologizantes do fracasso escolar, que eximem o estado da responsabilidade pelo descaso em que se encontram as escolas. Em meio a tantas repetições, quem não repete é o aluno no final do ano letivo.

\section{Referências}

Almeida Junior, A. (1957). Repetência ou Promoção Automática? Revista Brasileira de Estudos Pedagógicos, 27(65), 3-15.

André, M. E. D. A. (1995). Etnografia da prática escolar. São Paulo: Papirus.

Antunha, E.L.G., Lombardi, U., \& Bueno, H.P. (1961). Promoção automática. São Paulo: Serviço de Expansão Cultural (SEC).

Barreto, E.S.S., \& Mitrulis, E. (2001). Trajetórias e desafios dos ciclos escolares no País. Estudos Avançados, 15 (42), 103-140.

Barreto, E.S.S., \& Sousa, S.Z.M. (2004). Estudos sobre Ciclos e progressão escolar no Brasil: uma revisão. Educação e Pesquisa, $30(1), 31-50$

Bogdan, R., \& Biklen, S. (1994). Investigação qualitativa em educação. Porto: Porto Editora, 1994.
Collares, C.A.L., \& Moysés, M.A.A. (1996). Preconceitos no cotidiano escolar: ensino e medicalização. São Paulo: Cortez.

Conselho Estadual de Educação (1997). Regime de Progressão Continuada. Legislação do Ensino de Fundamental e Médio, 1505 .

Duarte, N. (2004). Vigotski e o aprender a aprender. crítica às apropriações neoliberais e pós-modernas da teoria vigotskiana. Campinas: Autores Associados.

Ezpeleta, J., \& Rockwell, E. (1986). Pesquisa Participante. São Paulo: Cortez.

Gonçalves Filho, J.M. (2007). Humilhação social: humilhação política. Em B. P. Souza (Org.) Orientação à queixa escolar (pp. 187-221). São Paulo: Casa do Psicólogo.

Guarido, R. (2010). A biologização da vida e algumas implicações do discurso médico sobre a educação. Em CRP- SP; GIQE (Orgs.). Medicalização de crianças e adolescentes: conflitos silenciados pela redução de questões sociais a doenças de indivíduos (pp. 27-39). São Paulo: Casa do Psicólogo.

Kubitschek, J. (1957) Reforma do Ensino Primário com base no sistema de Promoção Automática. Revista Brasileira de Estudos Pedagógicos, 27 (65), 141-145.

Leite, D.M. (1999). Promoção Automática e adequação do currículo ao desenvolvimento do aluno. Estudos em Avaliação Educacional, 19. São Paulo, 5-24.

Lüdke, M., \& André, M.E.D.A. (1986). Pesquisa em Educação: Abordagens Qualitativas. São Paulo: EPU.

Machado, A.M., \& Souza, M.P.R. (1997). Psicologia escolar. em busca de novos rumos. São Paulo: Casa do Psicólogo.

Mainardes, J. (2007). Reinterpretando os ciclos de aprendizagem. São Paulo: Cortez.

Meira, M.E.M., \& Antunes, M.A.M. (2003). Psicologia escolar: teorias críticas. São Paulo: Casa do Psicólogo.

Michelat, G. (1980). Sobre a Utilização da Entrevista Não-Diretiva em Sociologia. Em M.J.M Thiollent (Org.). Crítica Metodológica, Investigação Social e Enquete Operária. São Paulo: Polis.

Moysés, M.A.A. (2001). A Institucionalização invisível: crianças que não-aprendem-na-escola. São Paulo/Campinas: Mercado de Letras/FAPESP.

Moysés, M.A.A., \& Collares, C.A.L. (2010). Dislexia e TDAH: uma análise a partir da ciência médica. Em CRP- SP; GIQE (Org.). Medicalização de crianças e adolescentes: conflitos silenciados pela redução de questões sociais a doenças de indivíduos (pp. 71-110). São Paulo: Casa do Psicólogo. 
Patto, M.H.S. (1984). Psicologia e Ideologia: uma crítica à psicologia escolar. São Paulo: T. A. Queiroz.

Patto, M.H.S. (1990). A Produção do Fracasso Escolar. histórias de submissão e rebeldia. São Paulo: T. A. Queiroz.

Patto, M.H.S. (2005). Exercícios de indignação: escritos de educação e psicologia. São Paulo: Casa do Psicólogo.

Portal IDEB. Ideb e seus componentes: São Paulo. Recuperado: 24 jul. 2013. Disponível: http://www.portalideb.com.br/estado/125sao-paulo/ideb?etapa=5\& rede=estadual.

QEDU. Aprendizado dos alunos: São Paulo. Recuperado: 24 jul. 3013. Disponível: http://www.qedu.org.br/estado/125-sao-paulo/ aprendizado.

Sampaio Dória, A. (1918). Contra o analphabetismo. Anuário do Ensino do Estado de São Paulo (pp. 58-81). São Paulo: Diretoria da Instrução Pública.

Saviani, D. (2005). Pedagogia Histórico-crítica. Campinas: Autores Associados.

Secretaria de Estado da Educação (2013). Coordenadoria de Informação, Monitoramento eAvaliação Educacional. Desempenho Escolar - Estado de São Paulo 2010-2012. Recuperado: 24 jul. 2013. Disponível: http://www.educacao.sp.gov.br/a2sitebox/ arquivos/documentos/433.pdf.

Souza, B.P. (2007). Orientação à Queixa Escolar. São Paulo: Casa do Psicólogo.

Souza, M.P.R. (2002). Problemas de aprendizagem ou problemas de escolarização? Repensando o cotidiano escolar à luz da perspectiva histórico-crítica em psicologia. Em M. K. Oliveira, D. T. R.Souza, \& T.C. Rego (Orgs.) Psicologia, Educação e as temáticas da vida contemporânea (pp. 177-195). São Paulo: Moderna.

Tanamachi, E., Proença, M., \& Rocha, M. (2000). Psicologia e Educação: desafios teórico-práticos. São Paulo: Casa do Psicólogo.

Viégas, L. S. (2009). Progressão Continuada em uma perspectiva histórica. Revista Brasileira de Estudos Pedagógicos, 90, 489-510.

Viégas, L.S., \& Souza, M.P.R. (2012). Promoção Automática nos anos 1950: a experiência pioneira do Grupo Experimental da Lapa (São Paulo). Revista Educação e Pesquisa, 38 (2), 499-514.

Viégas, L. S., \& Souza, M. P. R. (2006). A Progressão Continuada no estado de São Paulo: considerações a partir da perspectiva de educadores. Psicologia Escolar e Educacional, 10, 247-262.

\section{Sobre a autora}

Lygia de Sousa Viégas (lyosviegas@gmail.com)

Doutora em Psicologia Escolar e do Desenvolvimento Humano pelo Instituto de Psicologia da Universidade de São Paulo, Professora Adjunta da Faculdade de Educação da Universidade Federal da Bahia (FACED-UFBA).

Financiamento: FAPESP

Artigo derivado de tese de doutorado, com reinterpretação dos dados. 